\title{
Continuous Solar Desalination of Brackish Water via a Monolithically Integrated Redox Flow Device
}

\section{Supporting Information}

\author{
Gowri Mohandass, ${ }^{\dagger}$ Taeyoung Kim, $\stackrel{*}{, \dagger}+$ Sitaraman Krishnan ${ }^{*} \dagger$ \\ $\dagger$ Department of Chemical \& Biomolecular Engineering, Clarkson University, Potsdam, New York \\ 13699, United States \\ \$Institute for a Sustainable Environment, Clarkson University, Potsdam, New York 13699, United States \\ *Corresponding Authors. Email: skrishna@clarkson.edu (S. Krishnan), tkim@clarkson.edu (T. Kim).
}

\section{Electrochemical Cell for Solar Redox Flow Desalination (RFD)}

Figure S1 shows the components of the electrochemical cell used for the solar desalination experiments. Their assembly is shown in Figure 1 of the main article.

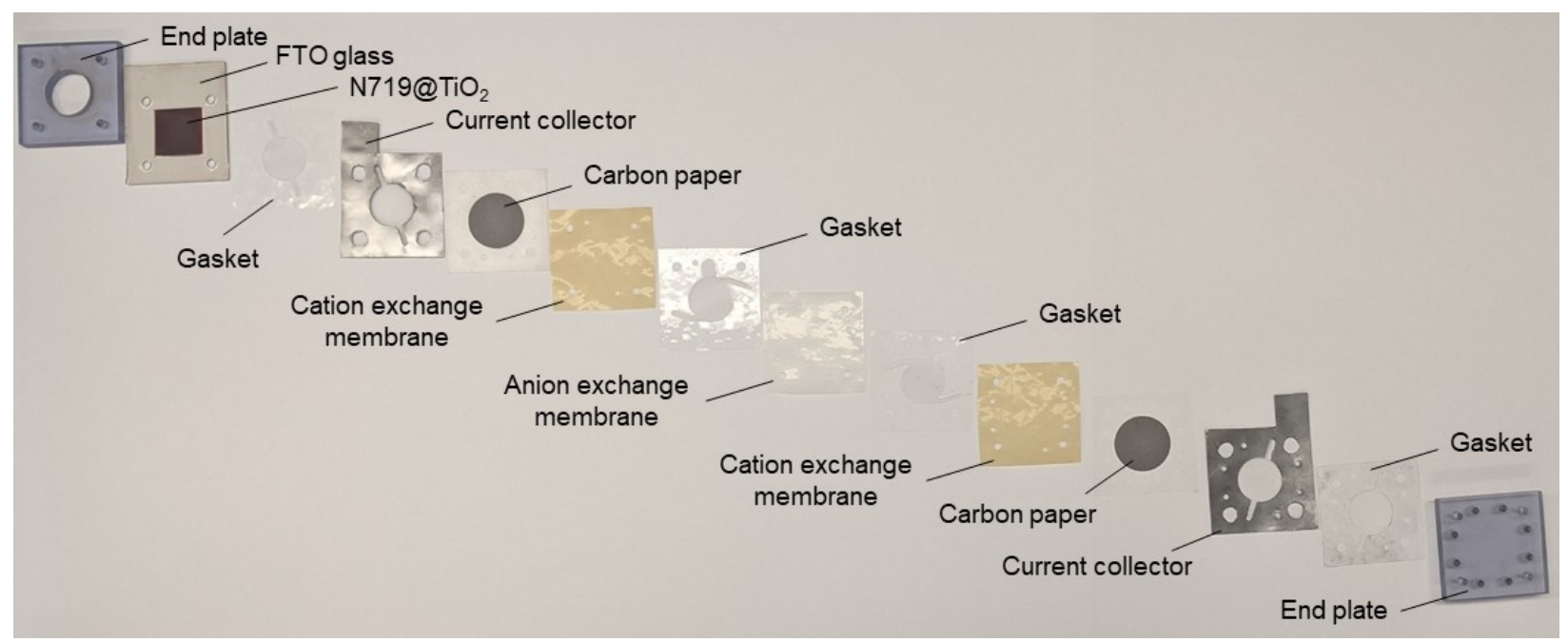

Figure S1. Constituents of the electrochemical cell for solar desalination. 


\section{Cell Current in Solar RFD for Different Feed Concentrations and Flow Rates}

Figure S2a shows the current profiles during solar RFD of $\mathrm{NaCl}$ solutions of two different concentrations at various throughput productivity values. Because of the cell's internal resistance variation with the salt concentration in the aqueous $\mathrm{NaCl}$ process streams, the current profiles showed significant differences upon changes in the feed concentration and flow rate. In Figure $\mathbf{S 2 b}$, the steady-state current (the mean of the current values measured between $\cong 6$ and 10 min of each experiment) is shown against productivity, $P$.
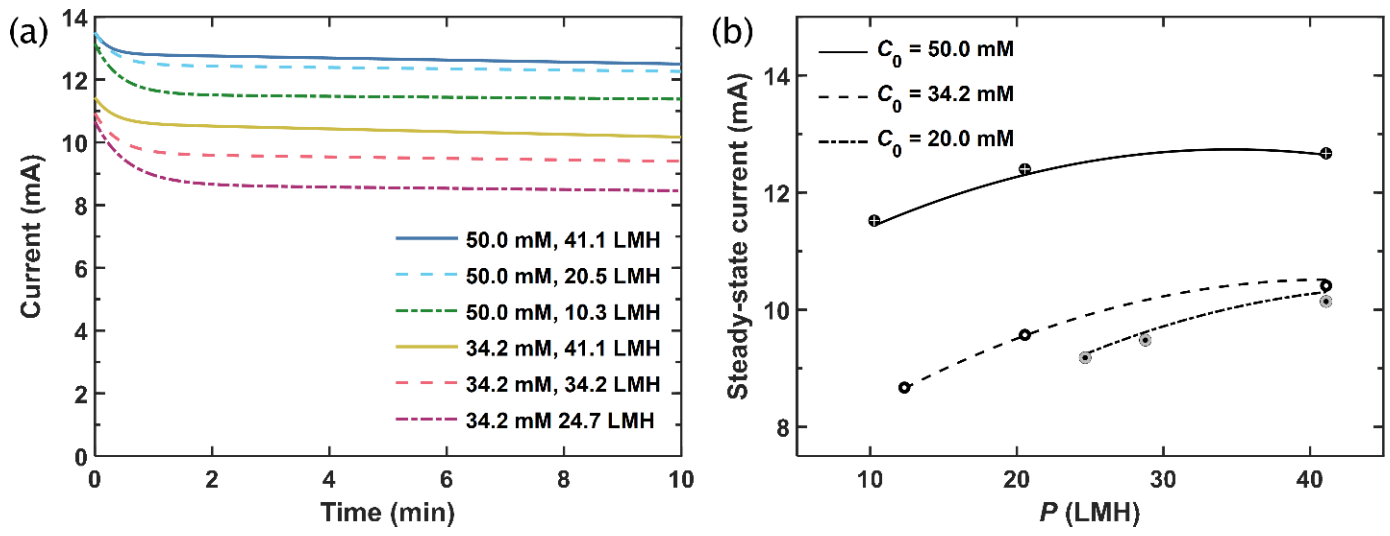

Figure S2. (a) Current profile during solar RFD of $\mathrm{NaCl}$ solutions of 50.0 and $34.2 \mathrm{mM}$ concentrations at different flow rates. (b) Steady-state current, $I_{\infty}$, vs productivity. $\mathrm{LMH}=$ liters of diluate per $\mathrm{m}^{2}$ of projected area per hour. The active photoanode area was $7.3 \mathrm{~cm}^{2}$. Time $t=0$ corresponds to the shorting of the circuit. Steady-state flow conditions were established prior to this time, by flowing the redox electrolyte and process streams through the electrochemical cell in open circuit, for at least 30 min under AM 1.5G (100 $\mathrm{mW} \mathrm{cm}{ }^{-2}$ ) illumination.

Regression analysis of the steady-state current data obtained from the current vs time plots yielded the following correlation for $I_{\infty}$

$$
\begin{gathered}
I_{\infty}=(10.11 \pm 0.02)+(1.03 \pm 0.02) \bar{P}+(1.67 \pm 0.01) \bar{C}_{0}+(0.91 \pm 0.02) \bar{C}_{0}^{2} \\
-(0.43 \pm 0.02) \bar{P} \bar{C}_{0}-(0.53 \pm 0.03) \bar{P}^{2}
\end{gathered}
$$

in terms of the parameters $\bar{P}$ and $\bar{C}_{0}$, which are the dimensionless productivity and feed concentrations, normalized using the experimental ranges of $P(\mathrm{LMH})$ and $C_{0}(\mathrm{mM})$, respectively, as follows:

$$
\begin{gathered}
\bar{P}=2\left(\frac{P-10.3}{41.1-10.3}\right)-1 \\
\bar{C}_{0}=2\left(\frac{C_{0}-20}{50-20}\right)-1
\end{gathered}
$$


Using the fact that the current density, $J_{\infty}$, is $I_{\infty}$ divided by the projected area of the electrode (equal to 7.3 $\mathrm{cm}^{2}$ ), eq S3 that correlates $J_{\infty}$ with $P$ and $C_{0}$ (in the units of $\mathrm{LMH}$ and $\mathrm{mM}$, respectively) is obtained.

$$
J_{\infty}=\left(6.2989+0.2472 P-0.1239 C_{0}+0.0040 C_{0}^{2}-0.0019 P C_{0}-0.0022 P^{2}\right) / 7.3
$$

Figure S3 is a parity plot for the measured steady-state current density and the current density predicted using eq S3.

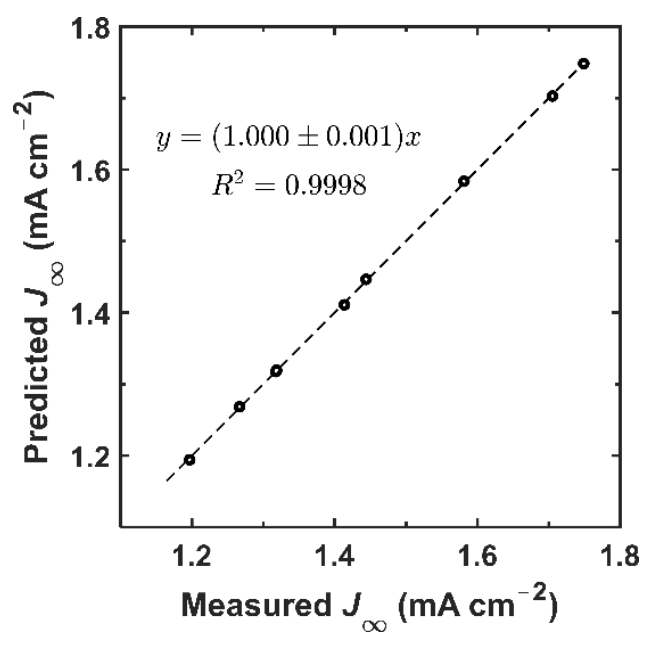

Figure S3. Measured and predicted current density during the solar RFD process for different productivity and feed concentration values; predictions are based on eq S3.

When an aqueous electrolyte is used, the relatively hydrophilic $\mathrm{N} 719$ dye is known to desorb from the $\mathrm{TiO}_{2}$ surface of the photoanode, resulting in a deterioration of the DSSC performance. ${ }^{1}$ However, Figure S2a shows that the photocurrents reached nearly constant values within the first few minutes of operation of the device, which suggests that the desorption of the dye if occurring over the duration of these measurements, was happening at a very slow rate. Note that the redox electrolyte and the process streams were flowing through the device for at least $30 \mathrm{~min}$ before starting the current measurements. The initial decrease of current, observed in Figure S2a, is primarily due to an increase in the cell's internal resistance due to changes in the concentrations of the process flow streams (rather than dye desorption). The subsequent slow decrease in the photocurrent (at a rate of $0.03 \pm 0.01 \mathrm{~mA} \mathrm{~min}^{-1}$ ) is attributed to dye desorption.

The short-circuit current density decreased by a factor of 2 or more after repeated use of the photoanode. In one experiment where the $J-V$ characteristics were acquired before and after about $2.5 \mathrm{~h}$ of solar RFD operation, the short-circuit current and the open-circuit voltage decreased by $\cong 34 \%$, the fill factor decreased by $\cong 21 \%$, and the power conversion efficiency decreased by $\cong 66 \%$. 


\section{Characterization of $\mathrm{I}^{-} / \mathrm{I}_{3}-$ Crossover in the Cation Exchange Membrane}

After contact with the electrolyte, the CEMs showed staining because of absorption of the electrolyte (Figure S4a). Therefore, the crossover of $\mathrm{I}^{-} / \mathrm{I}_{3}{ }^{-}$across the CEM was quantified using an electrochemical cell assembled as shown in Figure S4b.

The working electrode was a carbon paper heat-treated in air at $450{ }^{\circ} \mathrm{C}$ for $6 \mathrm{~h}$. The working electrode was in contact with the electrolyte solution consisting of $2 \mathrm{M}$ aqueous $\mathrm{NaI}$ and $0.2 \mathrm{M}$ aqueous iodine $(\cong 18 \mathrm{~mL})$. The counter electrode was a platinum wire mesh in contact with $50-\mathrm{mM}$ aqueous $\mathrm{NaCl}(\cong 18 \mathrm{~mL})$ and placed close to the CEM with the help of a gasket. Both the solutions were continuously stirred using a magnetic stirrer. The projected areas of the CEM and counter electrode were about $7 \mathrm{~cm}^{2}$. The current flow through the electrochemical cell was sustained by the $\mathrm{I}^{-} / \mathrm{I}_{3}^{-}$redox reaction at the carbon electrode and electrolysis of the $\mathrm{NaCl}$ solution at the Pt electrode.

At time $t=0$, a current of $7 \mathrm{~mA}$ (or $-7 \mathrm{~mA}$ ) was applied between the two electrodes. Approximately 3-mL aliquots of the $\mathrm{NaCl}$ solution were withdrawn at $t=15 \mathrm{~min}$ and $t=30 \mathrm{~min}$. The iodide concentrations in these samples were quantified by UV-vis spectroscopy using a PerkinElmer Lambda 650 UV-vis spectrophotometer and a quartz cuvette with a path length of $1 \mathrm{~cm}$. An aqueous solution of $5 \mathrm{mM} \mathrm{NaI}$ and $0.5 \mathrm{mM} \mathrm{I}_{2}$ was sequentially diluted in deionized water to different concentrations, and the UV-vis spectra of the resulting solutions were obtained (Figure S4c). Then, the UV-vis spectra of the analytes (quantitatively diluted to be within the calibration range) were also acquired (Figure S4e and Figure S4f). The measured absorption intensity was corrected by subtracting the absorption intensity of a blank solution (deionized water or $50-\mathrm{mM}$ aqueous $\mathrm{NaCl}$, as appropriate) at each measurement wavelength.

The UV-vis spectra were analyzed based on the peak assignments reported by Kireev and Shnyrev ${ }^{2}$ and our measurements of the absorption spectra of aqueous $\mathrm{NaI}$ and aqueous $\mathrm{I}_{2}$. The peak at $226 \mathrm{~nm}$ is attributed to the absorption of $\mathrm{I}^{-}$. Another absorbance peak of $\mathrm{I}^{-}$, below a wavelength of $180 \mathrm{~nm}$, is expected. ${ }^{2}$ Instead, a peak at $194 \mathrm{~nm}$ was observed in our measurements for aqueous $\mathrm{NaI}$. An aqueous solution of molecular $\mathrm{I}_{2}$ $(0.1 \mathrm{mM})$ exhibited a sharp absorption band at $204 \mathrm{~nm}$ and a broad band centered at $462 \mathrm{~nm}$, consistent with the observations of Kirrev and Shnyrev. Two absorbance peaks, centered at the wavelengths of 288 $\mathrm{nm}$ and $352 \mathrm{~nm}$, are expected for $\mathrm{I}_{3}^{-}{ }^{2}$ In the presence of excess iodide, Kirrev and Shnyrev found that the absorption spectra of $\mathrm{I}_{3}^{-}$additionally showed a peak at $226 \mathrm{~nm}$ whose intensity increased with an increase in the concentration of $\mathrm{I}^{-}$in the solution (while the intensities of the $288 \mathrm{~nm}$ and $352 \mathrm{~nm}$ peaks remained unchanged). 
(a)

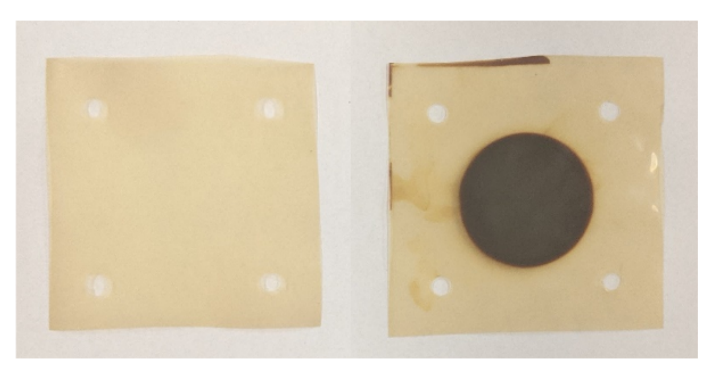

(c)

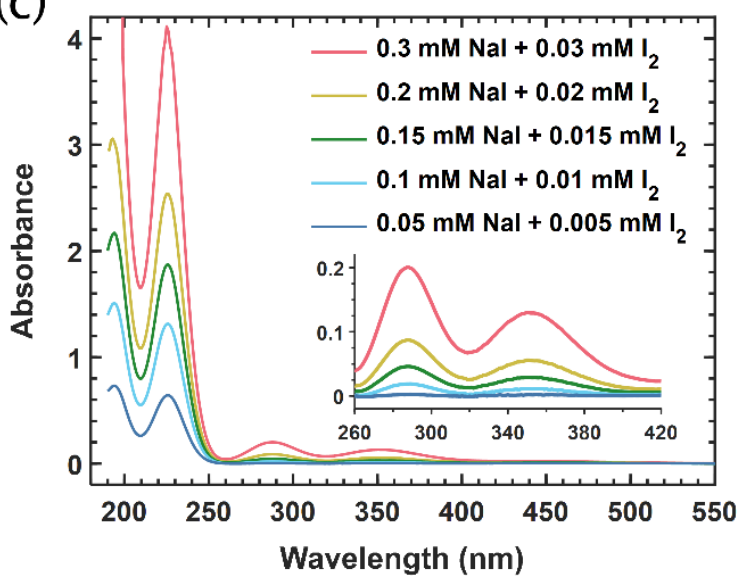

(e)

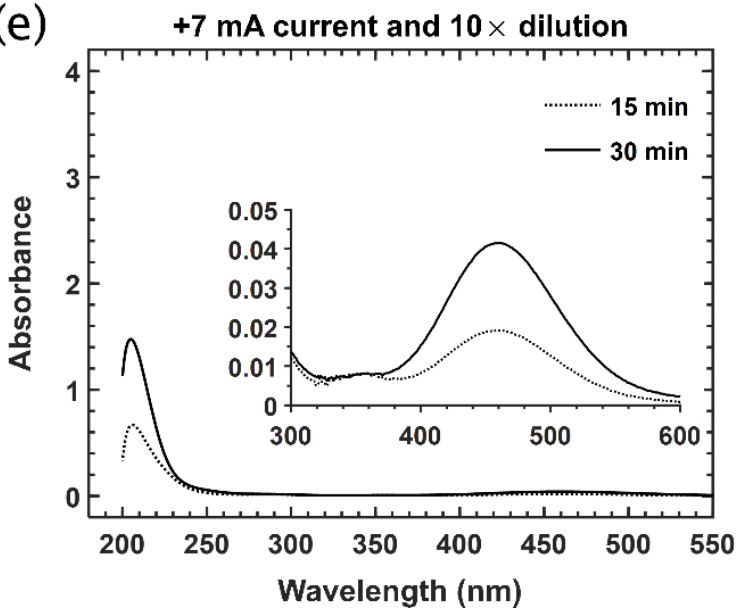

(b)
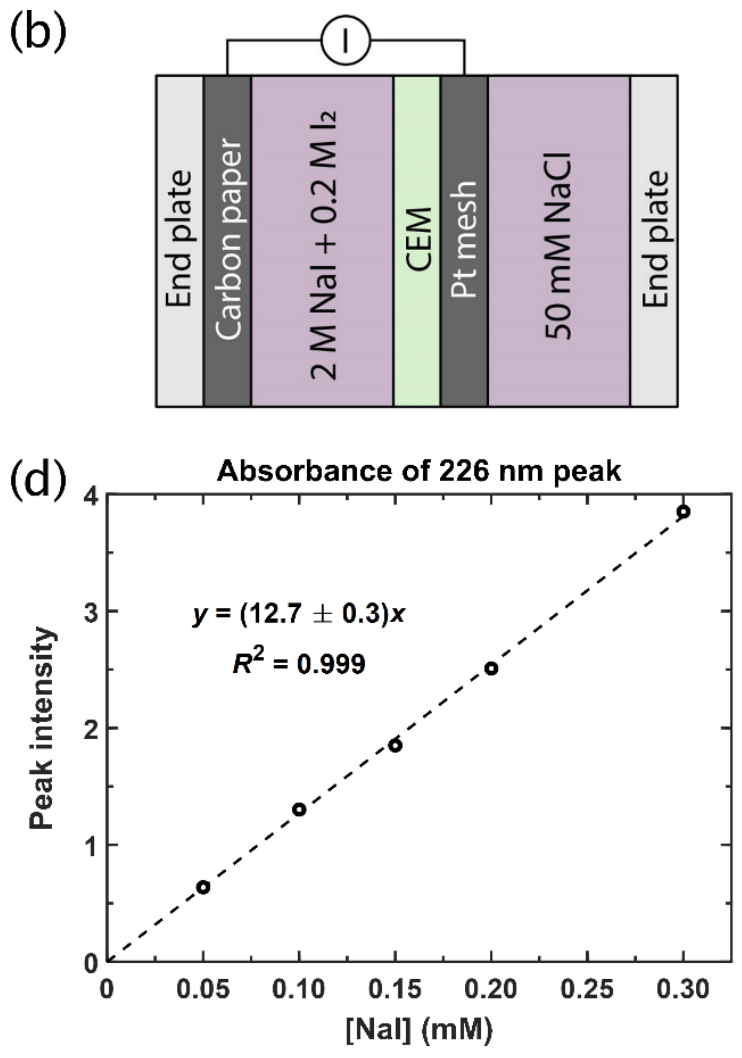

(f)

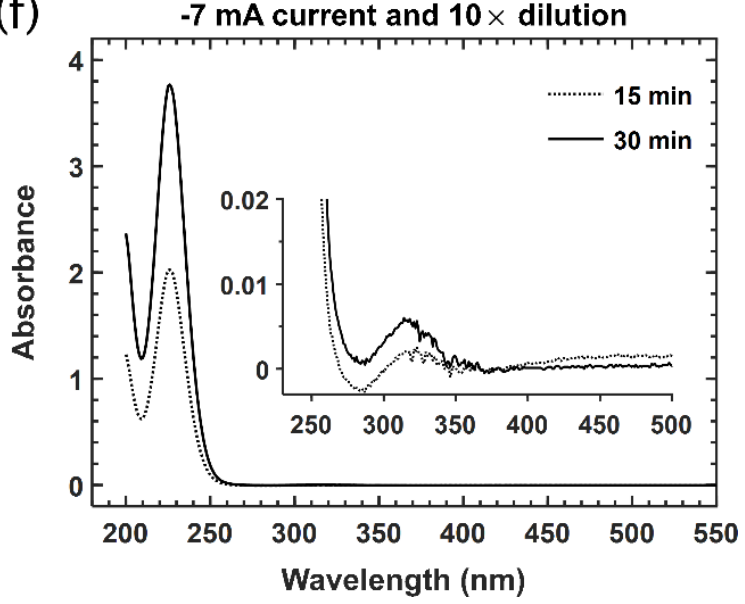

Figure S4. Quantification of $\mathrm{I}^{-} / \mathrm{I}_{3}^{-}$transport through the CEM. (a) Photographs of the CEM before (left) and after (right) contact with the $\mathrm{I}^{-} / \mathrm{I}_{3}^{-}$redox electrolyte. (b) Schematic of the electrochemical cell used for measuring $\mathrm{I}^{-} / \mathrm{I}_{3}{ }^{-}$permeation through the CEM. (c) UV-Vis absorption spectra of $\mathrm{I}^{-} / \mathrm{I}_{3}{ }^{-}$solutions of different concentrations, with a fixed molar ratio $[\mathrm{Nal}] /\left[\mathrm{I}_{2}\right]$ of 10:1. (d) Absorbance of the $\mathrm{I}^{-}$absorption peak at 226 $\mathrm{nm}$ vs the concentration of $\mathrm{Nal}$ in the redox electrolyte. (e and f) UV-vis absorption spectra of aqueous $\mathrm{NaCl}$ analytes, after passing $+7 \mathrm{~mA}$ and $-7 \mathrm{~mA}$ currents between the carbon and Pt electrodes for 15 and 30 min. All spectra shown are after blank correction. 
The UV-vis spectrum of the analytes collected from permeability measurements conducted by applying a current of $+7 \mathrm{~mA}$ indicated the presence of, predominantly, the nonionic $\mathrm{I}_{2}$ in the $\mathrm{NaCl}$ solution. The characteristics peaks of iodine at $\cong 204 \mathrm{~nm}$ and $462 \mathrm{~nm}$ were observed (Figure S4e). Absorbance corresponding to $\mathrm{I}^{-}$(at $226 \mathrm{~nm}$ ) was practically absent in the acquired spectra. The peaks corresponding to $\mathrm{I}_{3}^{-}$were also absent. These observations were consistent with the fact that, in the case of a positive current, the iodide ions diffuse toward the carbon electrode (Figure S4b), away from the CEM and the aqueous $\mathrm{NaCl}$ compartment.

In contrast, the UV-vis spectrum of the analytes collected from measurements conducted by applying a current of $-7 \mathrm{~mA}$ indicated the presence of mainly $\mathrm{I}^{-}$in the $\mathrm{NaCl}$ solution. By applying a negative current, the anions are driven toward the Pt electrode by the applied electric field, but the CEM resists the transfer of the anions in the redox electrolyte compartment into the $\mathrm{NaCl}$ solution. The peak at $226 \mathrm{~nm}$ was prominently seen (Figure S4f), but no $\mathrm{I}_{3}^{-}$was detected in the aqueous $\mathrm{NaCl}$ solution (no absorption peaks were observed at 288 and $352 \mathrm{~nm}$, as seen from the inset of Figure S4f). The consumption of iodine toward the formation of iodate $\left(\mathrm{IO}_{3}^{-}\right)$is possible through the reaction $\mathrm{I}_{2}+6 \mathrm{H}_{2} \mathrm{O} \rightarrow 2 \mathrm{IO}_{3}^{-}+12 \mathrm{H}^{+}+10 \mathrm{e}^{-},{ }^{3}$ which would shift the equilibrium of $\mathrm{I}_{3}^{-} \leftrightharpoons \mathrm{I}_{2}+2 \mathrm{I}^{-}$toward the formation of $\mathrm{I}^{-}$and the disappearance of $\mathrm{I}_{3}^{-}$. The absorption spectrum of iodate is a monotonically decreasing intensity with an increase in the wavelength in the range of 180 to $240 \mathrm{~nm}^{2}$ The absorption of $\mathrm{I}^{-}$is also observed in this range. Hence, our UV-vis spectroscopy measurements cannot conclusively rule out the crossover of $\mathrm{I}_{3}^{-}$through the CEM, but because of its larger size, the permeability of $\mathrm{I}_{3}^{-}$would be lower than that of $\mathrm{I}^{-}$.

Thus, when the applied electric field opposed the transport of iodide through the CEM (+7 mA current), negligible $\mathrm{I}^{-}$or $\mathrm{I}_{3}^{-}$was present in the aqueous $\mathrm{NaCl}$ solution. A small amount of iodine did permeate through the membrane - the concentration of $\mathrm{I}_{2}$ in the $\mathrm{NaCl}$ solution was estimated to be $\cong 0.7 \mathrm{mM}$ after 15 min and $\cong 1.4 \mathrm{mM}$ after $30 \mathrm{~min}$ of contact with the redox electrolyte (separated by the CEM). When the direction of the applied electric field was reversed ( $-7 \mathrm{~mA}$ current), electrophoresis resulted in the permeation of some $\mathrm{I}^{-}$through the CEM. The intensity of the peak at $226 \mathrm{~nm}$ was used for quantification of the iodide crossover. An excellent linear correlation of the intensity of this peak with the sodium iodide concentration in the electrolyte was observed (Figure $\mathbf{S 4 d}$ ). The concentration of $\mathrm{I}^{-}$in the $\mathrm{NaCl}$ solution was calculated to be $\cong 1.5 \mathrm{mM}$ after $15 \mathrm{~min}$ and $\cong 3.0 \mathrm{mM}$ after $30 \mathrm{~min}$.

\section{Solar RFD Concentration Profiles}

Figure S5 shows the diluate and concentrate concentration profiles measured during solar RFD of feed solutions with $34.2 \mathrm{mM}$ and $20.0 \mathrm{mM} \mathrm{NaCl}$ concentrations at different flow rates. 

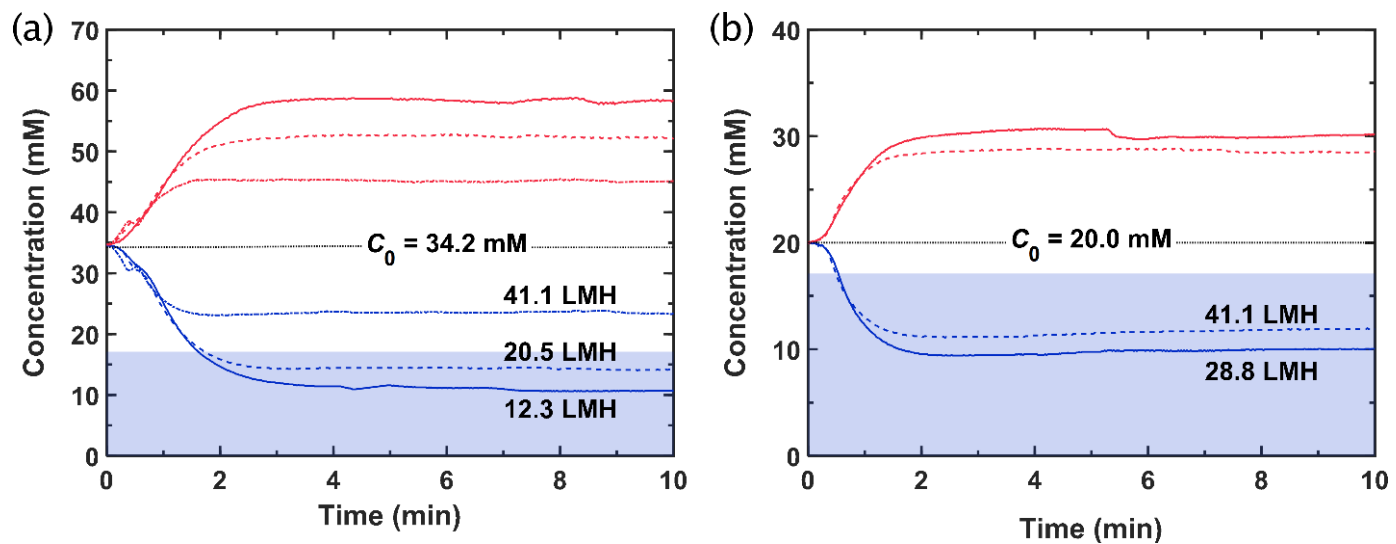

Figure S5. The evolution of $\mathrm{NaCl}$ concentration in the diluate (blue) and concentrate (red) effluent streams during solar RFD of feed solutions with initial $\mathrm{NaCl}$ concentrations of (a) $34.2 \mathrm{mM}$ and (b) $20 \mathrm{mM}$, at different throughput productivity values.

\section{Relationship Between Effluent Concentration, Feed Concentration, and Flow Rate in Solar RFD}

Theoretically, the diluate concentration, $C_{\infty}$, is related to the feed concentration, $C_{0}$, and flow rate, $Q$, by

$$
Q\left(C_{0}-C_{\infty}\right)=\frac{\lambda I_{\infty}}{F}
$$

and the plot of $Q\left(C_{0}-C_{\infty}\right) F$ against $I_{\infty}$ should be linear with a slope of $\lambda$, if the charge efficiency, $\lambda$, is a constant. Since $Q=P A$ and $I=J_{\infty} A$, where $P$ is the throughput productivity, $J_{\infty}$ is the current density, and $A$ is the projected area of flow through the device, eq $\mathrm{S} 4$ can be written as

$$
P\left(C_{0}-C_{\infty}\right)=\frac{\lambda J_{\infty}}{F}
$$

Thus, a correction of $P C_{\infty}$ with the factors affecting the steady-state current (eq S3) is expected. Regression analysis of the steady-state salt flow rate, $P C_{\infty}$, in the diluate with the feed concentration, $C_{0}$, in the range of 20 to $50 \mathrm{mM}$, and productivity, $P$, in the range of about 10.3 to $41.1 \mathrm{LMH}$ resulted in:

$$
P C_{\infty}=(517 \pm 10)+(477 \pm 20) \bar{P}+(286 \pm 20) \bar{C}_{0}+(234 \pm 20) \bar{P} \bar{C}_{0}
$$

where $\bar{P}$ and $\bar{C}_{0}$ are dimensionless productivity and feed concentrations, defined in eq S2. Eq S6 shows the expected trend of an increase in the diluate salt concentration with increasing feed concentration and increasing throughput productivity. A simplified form of eq S6, where $P$ and $C_{0}$ are in the units of LMH and $\mathrm{mM}$, respectively, is: 


$$
C_{\infty}=1.0134 C_{0}-\frac{6.9615 C_{0}}{P}-\frac{36.6539}{P}-4.4447
$$

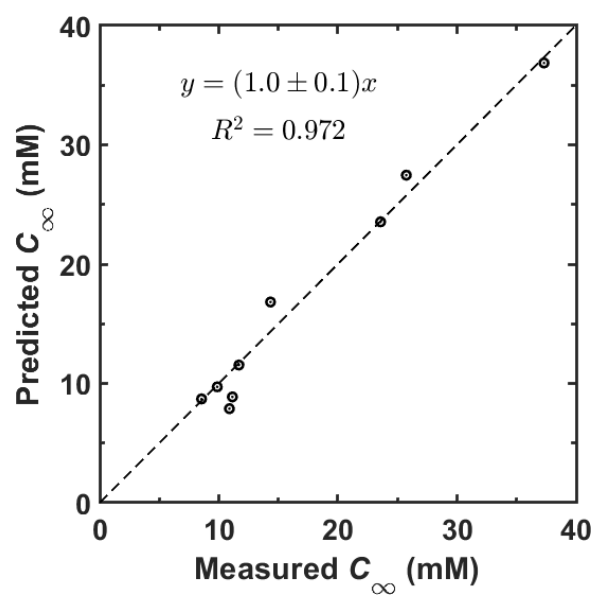

Figure S6. Parity plot for predicted and measured diluate concentration during the solar RFD of $\mathrm{NaCl}$ solutions of different feed concentrations and throughput productivity values; predictions are based on eq S7.

Figure S6 compares the salt concentration in the diluate predicted using the model in eq S7 with the experimentally determined diluate concentration. A good agreement between the predicted and measured values is seen.

\section{J-V Characteristics of the DSSCs Using the N719-Sensitized Photoanode and Nonaqueous Electrolytes}

A platinized FTO counter electrode was prepared by spreading a 5-mM solution of chloroplatinic acid hexahydrate $\left(\mathrm{H}_{2} \mathrm{Cl}_{6} \mathrm{Pt} \cdot 6 \mathrm{H}_{2} \mathrm{O}, 99.5 \%\right.$, Sigma-Aldrich $)$ in ethanol on a cleaned FTO glass substrate, followed by heating to $400{ }^{\circ} \mathrm{C}$ for $15 \mathrm{~min}$. The photoanode prepared using the procedure reported in the article was interfaced with the counter electrode with a gap of $25 \mu \mathrm{m}$ (created by a polytetrafluoroethylene gasket) filled with the redox electrolyte. Two different nonaqueous electrolytes were tested. The first electrolyte was based on the composition reported by Kang et al. ${ }^{4}$ It consisted of $0.6 \mathrm{M}$ 1-butyl-3-methylimidazolium iodide (bmimI, $99 \%$, Aldrich), $30.0 \mathrm{mM}$ iodine, $0.5 \mathrm{M}$ guanidine thiocyanate (GTC, $99 \%$, Alfa Aesar), and $0.5 \mathrm{M}$ 4-tert-butylpyridine (TBP, $98 \%$, Aldrich) in a blend of acetonitrile ( $85 \mathrm{vol} \%$ ) and valeronitrile (15 vol \%) (ACN-VN). In the second electrolyte, the iodide (bmimI) and iodine concentrations were the same as that of the aqueous electrolyte of the present study, that is, $2.0 \mathrm{M}$ and $0.2 \mathrm{M}$, respectively. Two cells incorporating each electrolyte were tested. Figure S7 shows the $J-V$ curves of the better-performing cells, and Table S1 shows the mean values of the photovoltaic parameters of the DSSC prepared using each electrolyte. 

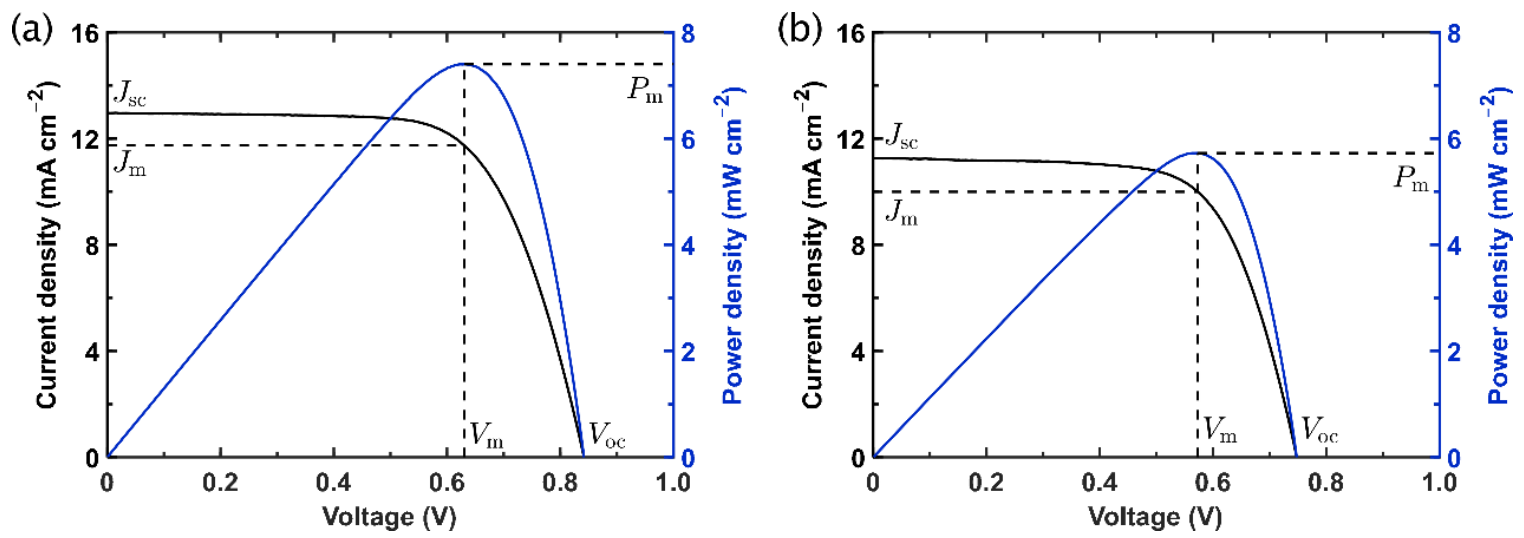

Figure S7. $J-V$ characteristics of the N719-sensitized solar cells prepared using two different electrolytes, under AM 1.5G illumination (100 $\mathrm{mW} \mathrm{cm}^{-2}$ ) and $20 \mathrm{mV} \mathrm{s}^{-1}$ scan rate: (a) 0.6 M bmiml, $30.0 \mathrm{mM}$ iodine, 0.1 $\mathrm{M}$ GTC, and 0.5 M TBP in ACN-VN; (b) 2.0 M bmiml, 0.2 M iodine, 0.1 M GTC, and 0.5 M TBP in ACN-VN.

Table S1. Photovoltaic parameters of DSSCs assembled using two nonaqueous electrolytes comprising a solution of bmiml, iodine, GTC, and TBP in 85:15 volume ratio acetonitrile-valeronitrile solvent.

\begin{tabular}{lllll} 
& $V_{\mathrm{oc}}(\mathrm{mV})$ & $J_{\mathrm{oc}}\left(\mathrm{mA} \mathrm{cm}^{-2}\right)$ & $F F$ & $\eta(\%)$ \\
\hline 0.6 M bmimI, 30 mM iodine, & $0.842 \pm 0.001$ & $12.1 \pm 0.8$ & $0.674 \pm 0.003$ & $6.9 \pm 0.5$ \\
0.5 M GTC, and 0.5 M TBP & & & & \\
$2.0 \mathrm{M}$ bmimI, 0.2 M iodine, & $0.745 \pm 0.005$ & $11.4 \pm 0.1$ & $0.671 \pm 0.009$ & $5.7 \pm 0.1$
\end{tabular}

$0.5 \mathrm{M}$ GTC, and $0.5 \mathrm{M}$ TBP

\section{Concentration vs Time Profiles in Nonsolar RFD Mode}

Figure $\mathbf{S 8}$ shows the $\mathrm{NaCl}$ concentration in the diluate and concentrate effluent streams at different applied current densities in the current-controlled nonsolar RFD experiments.

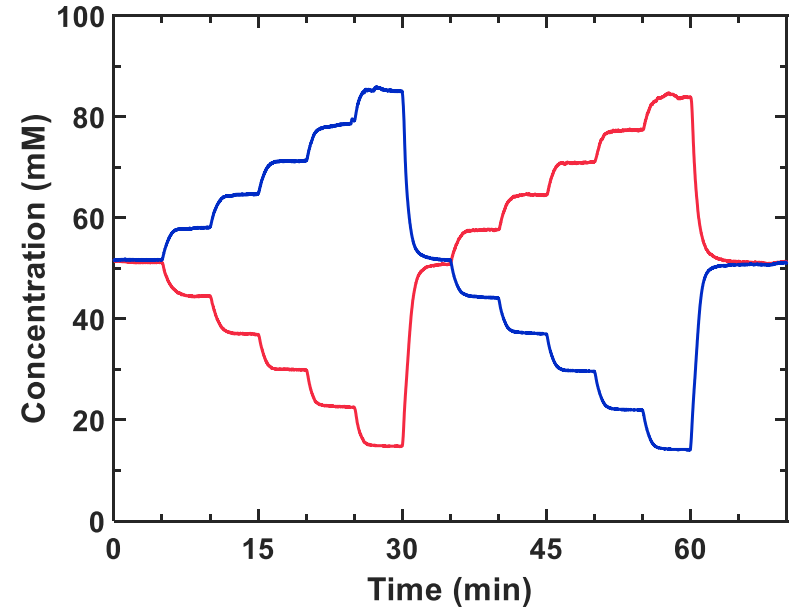

Figure S8. $\mathrm{NaCl}$ concentration in the diluate and concentrate effluent streams for various applied current density values, positive and negative, during RFD of a 50-mM aqueous solution of $\mathrm{NaCl}$ at $41.1 \mathrm{LMH}$ flow rate. 
The current density was increased in increments of $\cong 0.96 \mathrm{~mA} \mathrm{~cm}{ }^{-2}$ up to a value of $\cong 4.8 \mathrm{~mA} \mathrm{~cm}{ }^{-2}$. At $t=$ $30 \mathrm{~min}$, the direction of current flow through the cell was reversed. The concentration profiles for both data sets (acquired using positive and negative currents) were nearly identical for each magnitude of current density. The steady-state concentration was determined by averaging the values obtained from the two concentration profiles.

The process dynamics of the overall system, including the conductivity sensing, were found to be firstorder, wherein the concentration profiles of the effluent streams showed an exponential variation with time. At each current density, the diluate concentration variation during the constant current holding step showed an excellent fit $\left(R^{2}>0.99\right.$ in all cases) to eq $\mathrm{S} 8$ :

$$
C(t)=C_{\infty}+\left[C(0)-C_{\infty}\right] e^{-t / \tau}
$$

where $C(t)$ is the diluate concentration at time, $t, C(0)$ is the concentration at the start of the constantcurrent step, $C_{\infty}$ is the steady-state concentration, and $\tau$ is the system time constant. In Figure S9a, the five diluate concentration transients for the different current densities show an exponential decrease attaining a steady-state concentration within about $300 \mathrm{~s}$. For each transient, the concentration profile was normalized using the concentration, $C(0)$, at the start of the transient and concentration, $C_{\infty}$, at the end (eq S9):

$$
C^{*}(t)=\frac{C(t)-C_{\infty}}{C(0)-C_{\infty}}
$$
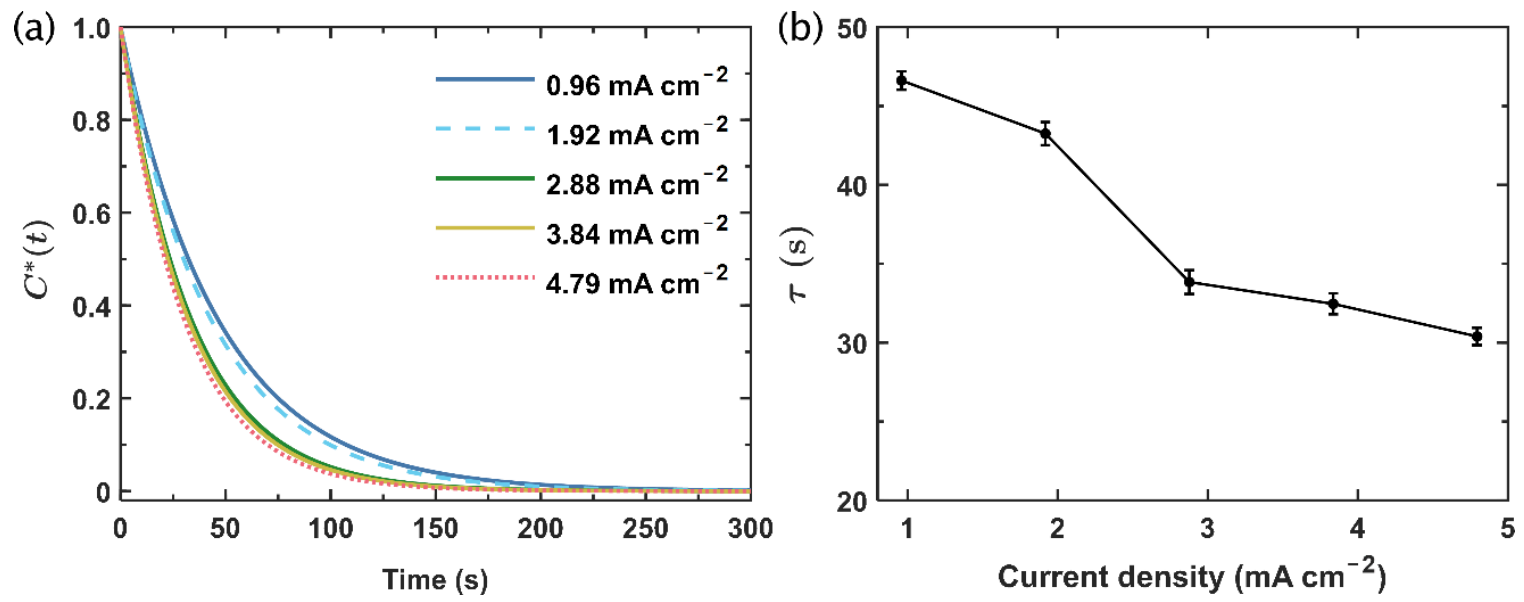

Figure S9. (a) Time evolution of the diluate concentration profile for different constant current densities during RFD of a 50-mM aqueous solution of $\mathrm{NaCl}$ at $41.1 \mathrm{LMH}$ flow rate. (b) The variation of the time constant of the first-order system with applied current density. 
Figure S9b shows that the time constant decreased from $\cong 47 \mathrm{~s}$ to $\cong 30 \mathrm{~s}$ as the applied current density

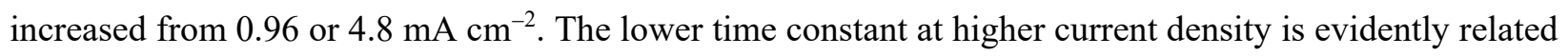
to higher overall ion transport rates.

\section{Measurement of Voltage Drop Due to Redox Reaction}

A two-channel flow cell separated by a cation exchange membrane was used for determining the voltage required for the redox reaction (Figure S10). Porous carbon paper electrodes were attached to the cation exchange membrane on both sides. The aqueous redox electrolyte comprising of $2.0 \mathrm{M} \mathrm{NaI}$ and $0.2 \mathrm{M} \mathrm{I}_{2}$ was recirculated between the two channels at a flow rate of $0.5 \mathrm{~mL} \mathrm{~min}{ }^{-1}$. The current was increased stepwise from 7 to $35 \mathrm{~mA}$, and the potential difference at each current was measured.

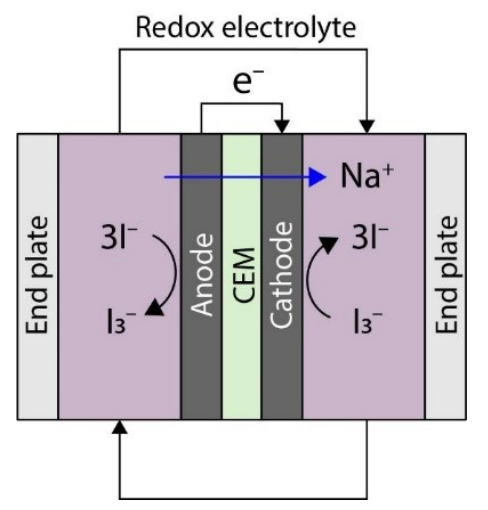

Figure S10. Schematic of the experimental set-up used to measure voltage drop due to the $\mathrm{I}^{-} / \mathrm{I}_{3}^{-}$redox reaction.

The voltage showed a linear increase with current density, as shown in Figure S11.

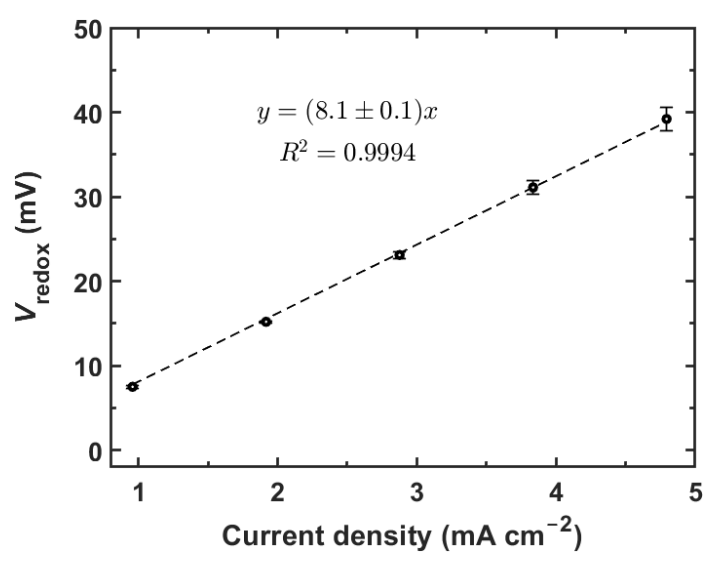

https://doi.org/10.1021/acsestengg.1c00266
Figure S11. Effect of current density on the voltage required to drive the $\mathrm{I}^{-} / \mathrm{I}_{3}^{-}$redox reaction at the carbon electrode. 


\section{References}

1. Galliano, S.; Bella, F.; Gerbaldi, C.; Falco, M.; Viscardi, G.; Grätzel, M.; Barolo, C., Photoanode/Electrolyte Interface Stability in Aqueous Dye-Sensitized Solar Cells. Energy Technology 2017, 5 (2), 300-311.

2. Kireev, S. V.; Shnyrev, S. L., Study of Molecular Iodine, Iodate Ions, Iodide Ions, and Triiodide Ions Solutions Absorption in the UV and Visible Light Spectral Bands. Laser Physics 2015, 25 (7), 075602.

3. Lee, J.; Srimuk, P.; Carpier, S.; Choi, J.; Zornitta, R. L.; Kim, C.; Aslan, M.; Presser, V., Confined Redox Reactions of Iodide in Carbon Nanopores for Fast and Energy-Efficient Desalination of Brackish Water and Seawater. ChemSusChem 2018, 11 (19), 3460-3472.

4. Kang, J. S.; Kim, J.-Y.; Yoon, J.; Kim, J.; Yang, J.; Chung, D. Y.; Kim, M.-c.; Jeong, H.; Son, Y. J.; Kim, B. G.; Jeong, J.; Hyeon, T.; Choi, M.; Ko, M. J.; Sung, Y.-E., Room-Temperature Vapor Deposition of Cobalt Nitride Nanofilms for Mesoscopic and Perovskite Solar Cells. Advanced Energy Materials 2018, 8 (13), 1703114. 